REMOA

\title{
UM OLHAR SOBRE A UTILIZAÇÃO DE AGROTÓXICOS NO MUNICÍPIO DE NOVO BARREIRO/RS, ATRAVÉS DO PROJETO DE EDUCAÇÃO AMBIENTAL, APLICADO NAS SÉRIES FINAS DO ENSINO FUNDAMENTAL NA ESCOLA MUNICIPAL DE ENSINO FUNDAMENTAL ZEFERINO BRASIL. ${ }^{1}$
}

\author{
Aline Franz ${ }^{2}$, Dionísio Link ${ }^{3}$ \\ Trabalho de Monografia, Curso de Pós-graduação - Especialização em Educação Ambiental - \\ Centro de \\ Ciências Rurais / UFSM. \\ 22Autora: Graduada em História, Especialista em História do Brasil e as Perspectivas Regionais e \\ Educação \\ Ambiental - UFSM. \\ Orientador: Professor da UFSM, Doutor em Ecologia.
}

\section{RESUMO}

O presente compõe-se do estudo sobre os agrotóxicos, seu surgimento, classificação, utilização correta de equipamentos de proteção individual, destinação final das embalagens de agrotóxicos, ação dos agrotóxicos na natureza e seus prejuízos a saúde humana. Foi desenvolvido visando refletir sobre sua ação modificadora no meio ambiente, buscando uma interação família escola como contribuição para a formação da consciência ambiental. As atividades se realizaram na Escola Municipal de Ensino Fundamental Zeferino Brasil da localidade de Três Passinhos, município de Novo Barreiro. A metodologia utilizada para o desenvolvimento desse projeto fundamentou-se na abordagem qualitativa da pesquisa, a qual foi composta por vários encontros. O tema agrotóxicos é de grande importância em âmbito internacional, nacional, regional, estadual e municipal, por isso, a escolha do tema. A tendência crescente do uso desses produtos com os mais diversos propósitos da atualidade, inclusive como armas de extermínio humano individual (tentativa de suicídio) ou coletivo (bioterrorismo), reforça a ênfase a iniciativa deste trabalho. Sabe-se que muitos problemas na aplicação dos agrotóxicos ocorrem devido ao alto índice de desinformação do agricultor principalmente no meio rural, onde as aplicações cada vez mais intensas de agrotóxicos e de outros produtos químicos na agricultura resultaram na contaminação do solo, água e do meio ambiente de forma generalizada por mais de uma classe de substâncias tóxicas, além de representarem um dos grandes problemas atuais para a saúde daqueles que lidam diretamente com tais substâncias.

Palavras-chave: uso adequado; proteção ambiental; conhecimento. 


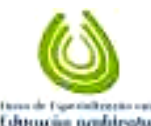

FRANZ \& LINK, vol.(4), n4, p. 672-695, 2011.

REMOA

\section{Monografias Ambientais (e-ISSN: 2236-1308)}

\section{INTRODUÇÃO}

Para satisfazer suas necessidades básicas o homem desde o seu surgimento, entra na história como um ser que transforma e altera o equilíbrio dos recursos naturais, produzindo degradação ambiental, destruição dos ecossistemas e a extinção das espécies. Entre as características desta degradação destaca-se a aplicação de agrotóxicos nas lavouras, pomares e jardins.

A sociedade atual está centrada no desejo de obtenção do lucro o que resulta na agressão ambiental, com efeitos danosos ao ambiente através da poluição do solo, da água e do ar. A população do município de Novo Barreiro/RS sobrevive da atividade primária e vem

convivendo com uma problemática tem causado conseqüências negativas a seus cidadãos e preocupação aos governantes devido o uso descontrolado e incorreto dos agrotóxicos, já que sua utilização se caracteriza por um considerável desperdício de energia e de produto químico, constituindo-se em sério risco de acidente para o agricultor e o meio ambiente, devido ao desrespeito total do homem com 0 ambiente.

A toxicologia, por diferentes compostos químicos causa efeitos adversos para a saúde humana, exige hoje dos cidadãos buscar conhecimentos para identificar o problema e amenizar as conseqüências para as gerações futuras.

O uso indevido e inadequado de agrotóxicos é responsável pelos altos índices de intoxicações aguda ou processo de agudização do fenômeno crônico dos trabalhadores, além disso, os alimentos consumidos pela população são muitas vezes contaminados ocasionando danos econômicos e ambientais à sociedade.

Tornou-se muito comum, os agricultores após utilizarem o produto, descartá-los jogando as embalagens dentro dos rios, córregos ou sobre o solo, não dando o destino correto as embalagens, entregando-as a empresa onde adquiriu o produto, isso através da nota fiscal. Os produtos também são aplicados próximos a fonte de água e rios correndo o risco de contaminar a água, o solo e os cursos d'água, além da aplicação antes da irrigação (por aspersão) quando as gotas d'água lavam o produto das folhas, anulando o tratamento e contaminando o solo.

Deve-se esclarecer e levar ao conhecimento do agricultor a importância de certos cuidados referentes ao uso de agrotóxicos, tais como, as conseqüências da não utilização equipamentos de proteção individual e reutilização das embalagens, medidas de prevenção, via de absorção, reconhecimento de intoxicações e conseqüências de danos agudos e crônicos à saúde das famílias e ao meio ambiente. Necessita-se de conscientização através do desenvolvimento de ações, alternativas para superação da crise ambiental, necessidade esta que deve ser percebida não somente quando o aquecimento global ameaça a produtividade e a lucratividade das ações humanas, mas pensar em um meio ambiente habitável para as gerações futuras que irão nos suceder.

Precisa-se de mobilização coletiva, conscientização, enfim compromisso ambiental, para isso, as instituições educativas devem desenvolver a consciência de preservação ecológica através dos jovens e crianças, que serão os transmissores para suas famílias sobre a importância desse tema, pois estes cidadãos serão o futuro do país; necessita-se de um desenvolvimento sustentável, que assegure renda e emprego.

É grande a necessidade que educadores promovam debates, análises críticas em sala de aula, buscando conscientizar e desenvolver ações coletivas de proteção ao meio ambiente, 
REMOA

\section{Monografias Ambientais (e-ISSN: 2236-1308)}

principalmente na utilização de agrotóxicos, que quando aplicados sem os cuidados necessários podem trazer conseqüências negativas a saúde humana e ao meio ambiente, assim com um trabalho conjunto entre educadores, profissionais de saúde, técnicos e agrônomos, se conseguirá adotar uma nova postura sem prejuízos ecológicos que comprometem a sobrevivência humana as futuras gerações que dependem de ações do presente.

\section{Objetivo Geral}

Refletir e orientar junto aos educandos quanto ao uso correto de agrotóxicos, sua aplicação, e ação modificadora do meio ambiente, buscando interação escola/família como uma contribuição para a formação da consciência social e agroecológica a população barreirense.

\section{Objetivos Específicos}

Construir coletivamente alternativas eficientes que ofereçam subsídios para organização de ações que levem as pessoas a tomarem consciência da gravidade da situação ambiental e relacionar os prejuízos que uso indevido de agrotóxicos tem na degradação ambiental;

Promover encontros que visem reunir os educandos com o intuito de fazê-los perceber a gravidade da má utilização dos agrotóxicos para sua saúde, bem como, suas conseqüências negativas ao meio ambiente;

Desenvolver atividades educativas interdisciplinares para educandos, demonstrando que se bem aproveitados e preservados, os recursos do meio ambiente só trazem benefícios para a comunidade; Trabalhar o tema de forma reflexiva e participativa, fazendo o educando se sentir integrado com o ambiente, agindo com consciência e compromisso social.

\section{REVISÃO BIBLIOGRÁFICA}

Em pleno século XXI é visível a urgente necessidade de transformações através da criação de ações que resgatem o respeito pela vida, com justiça ambiental e social, a diversidade, a sustentabilidade e a beleza. Percebe-se também que esta não é uma missão fácil de ser colocada em prática a curto prazo, mas que com união, conscientização, valor ético e político, irá se conseguir satisfazer às necessidades básicas de todos os cidadãos em termos água, abrigo, alimento, saúde e energia.

Dentro deste contexto a educação desenvolve um papel fundamental tendo o compromisso de levar a sociedade a refletir sobre as questões sócio-ambientais urgentes e a participar de ações que contribuam para a melhoria da qualidade de vida de todos, precisa-se formar cidadãos conscientes frentes aos problemas ambientais.

A Educação Ambiental assume assim a sua parte no enfrentamento dessa crise radicalizando seu compromisso com mudanças de valores, comportamentos, sentimentos e atitudes, que deve se realizar junto à totalidade dos habitantes de cada base territorial, de forma permanente, continuada e para todos. Uma educação que se propõe a fomentar 


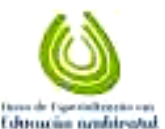

FRANZ \& LINK, vol.(4), n4, p. 672-695, 2011.

REMOA

\section{Monografias Ambientais (e-ISSN: 2236-1308)}

processos continuados que possibilitem o respeito à diversidade biológica, cultural, étnica, juntamente com o fortalecimento da resistência da sociedade a um modelo devastador das relações de seres humanos entre si e destes com o meio ambiente. (MED/MMA/UNESCO, 2007).

A escola deve oportunizar aos seus alunos a discussão sobre as questões ambientais, refletindo e buscando uma sociedade igualitária e ecologicamente equilibrada, pois defender o meio ambiente na atualidade significa qualidade de vida. Assim a Educação Ambiental deve ser acima de tudo um ato político voltado para a transformação social. Através da Educação Ambiental percebemos a necessidade de um trabalho vinculado aos princípios da dignidade do ser humano, da participação, da responsabilidade, da solidariedade e da qualidade de vida. Esta se volta para a transformação, o seu enfoque deve buscar uma perspectiva holística de ação, que relaciona o homem, a natureza e o universo, tendo em conta que os recursos naturais se esgotam e o homem é o agende desta degradação, assim temos a escola, que pode transformar-se em um espaço em que o docente terá condições de analisar a natureza entrelaçada nas práticas sociais, parte componente de uma realidade mais complexa e multifacetada, devemos despertar para ações em busca de alternativas e soluções. (KUHNNE, 2008).

De acordo com Capra (2006, p. 25) a visão holística concebe o mundo como um todo integrado, e não como uma coleção de partes dissociadas. Pode também ser denominada visão ecológica, se o termo "ecológica", for empregado um sentido muito mais amplo e mais profundo que o usual. A percepção ecológica profunda reconhece a interdependência fundamental de todos os fenômenos, e o fato de que, enquanto indivíduos e sociedades, estamos encaixados nos processos cíclicos da natureza (e, em última análise, somos dependentes desses processos). A ecologia profunda não separa os seres humanos ou qualquer outra coisa do meio ambiente natural. Ela vê o mundo não como uma coleção de objetos isolados, mas como uma rede de fenômenos que estão fundamentalmente interconectados e são interdependentes, reconhece o valor intrínseco de todos os seres vivos e concebe os seres humanos apenas como um fio particular na teia da vida.

Considerando a situação acima referida deve-se registrar a questão da utilização dos agrotóxicos, seu problema de contaminação ao meio ambiente e prejuízos a saúde humana, quando aplicado de maneira incorreta pelo ser humano que age de maneira descontrolada sobre o meio ambiente, com isso, acaba por desrespeitar a natureza comprometendo o meio ambiente para as gerações futuras.

\section{REFERENCIAL TEÓRICO}

A origem dos agrotóxicos é milenar, e até o final do século passado, era usado basicamente na forma de infusões a partir de vegetais macerados, onde o extrato retirado e diluído em água era aplicado nas desinfestações rurais e plantas cultivadas como inseticidas. A partir do início do século, a indústria mais evoluída, passou a desenvolver os agrotóxicos a partir de substâncias químicas manipuladas em laboratórios.

Os agrotóxicos tinham como característica uma grande concentração, e como resultado um grande poder mortífero. Já na Segunda Guerra Mundial, foram feitas tentativas de uso como 


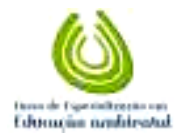

FRANZ \& LINK, vol.(4), n4, p. 672-695, 2011. Monografias Ambientais (e-ISNN: 2236-1308)

REMOA

arma de guerra, resultando em catástrofes. Na década de 50 os pesticidas, que na maioria eram sobras de guerras, passaram a ser usados nas lavouras para controlar pragas, doenças e inços. Os países que tinham a agricultura como principal base de sustentação econômica na África, Ásia e América Latina, sofreram fortes pressões de organismos financiadores internacionais para adquirir essas substâncias químicas. A alegação era que os agrotóxicos garantiam a produção de alimentos para combater a fome. Com o inofensivo nome de defensivos agrícolas, eles eram incluídos compulsoriamente, junto com adubos e fertilizantes minerais, nos financiamentos agrícolas. (INFORMATIVO, 1995).

No Brasil, foi na década de 70 que começou a ocorrer o uso intensivo dos agrotóxicos, em nome da Revolução Verde, alicerçada nas monoculturas de trigo e soja.

A chamada "Revolução Verde" foi um programa que tinha como objetivo explícito contribuir para o aumento da produção e da produtividade agrícola no mundo, através do desenvolvimento de experiências no campo da genética vegetal para a criação e multiplicação de sementes adequadas as condições dos diferentes solos e climas e resistentes às doenças e pragas, bem como da descoberta e aplicação de técnicas agrícolas ou tratos culturais mais modernos e eficientes. (BRUM, 1983, p. 55).

A partir das informações publicadas pela Associação Nacional de Defesa Vegetal (Andef) o agronegócio fez do Brasil o maior consumidor de venenos do mundo, posição ocupada antes pelos Estados Unidos, foi assumida em 2008, ano em que o mercado de agrotóxicos movimentou sete bilhões de dólares. (SITE PSOLSP, 2009).

Somos um país de clima favorável ao desenvolvimento de pragas agrícolas com temperatura elevada e umidade considerável. Os produtos onde são mais utilizados os agrotóxicos são os de exportação. Entre as regiões brasileiras com maior consumo de agrotóxicos está a região Sudeste, Sul, Centro-Oeste, sendo o estado de São Paulo um dos grandes consumidores com cerca de $36 \%$ de inseticida e $59 \%$ de fungicidas comercializados no país. (GONÇALVES, 2004).

A lei federal no. 7.802 de 11.07.89, regulamentada inicialmente através do decreto 98.816, no seu Artigo 2으, Inciso 1, define o termo agrotóxicos e afins da seguinte maneira:

\footnotetext{
São os produtos os agentes de processo físicos, químicos ou biológicos destinados ao uso nos setores de produção, armazenamento e beneficiamento de produtos agrícolas, nas pastagens, na proteção de florestas nativas ou implantadas e de outros ecossistemas e também em ambientes urbanos, hídricos e industriais, cuja finalidade seja alterar a composição da flora e da fauna, a fim, de preservá-la da ação danosa de seres vivos nocivos, bem como, de substâncias e produtos empregados como desfolhastes, dessecantes, estimuladores e inibidores do crescimento.
}

O termo agrotóxico ao invés de defensivo agrícola passou a ser utilizado, no Brasil, para denominar os venenos agrícolas, após grande mobilização da sociedade civil organizada (SIQUEIRA \& KRUSE, 2009). Mais do que uma simples mudança de terminologia, esse termo coloca em evidencia a toxicidade desses produtos para o meio ambiente e a saúde humana.

Sem aumentar a área plantada nas últimas safras, o agricultor brasileiro conseguiu obter maior produtividade, demonstrando uma evolução significativa no uso de tecnologia de produção. Entre as safras de 2004 e 2009, a produção de alimentos no país cresceu $20 \%$, apesar da queda de $2 \%$ na área plantada. Com isso, o Brasil tornou-se o principal mercado mundial de 


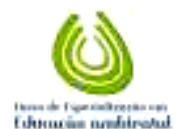

\section{FRANZ \& LINK, vol.(4), n4, p. 672-695, 2011. Monografias Ambientais (e-ISSN: 2236-1308)}

REMOA

defensivos um dos itens mais importantes na geração de ganhos tecnológicos no campo, segundo aponta estudo realizado pela multinacional alemã Kleffmann. Segundo a pesquisa de $60 \%$ a $80 \%$ da decisão de compra de defensivos dos produtores tem como objetivo obter maior rendimento possível na lavoura. (GLOBO RURAL, 2009)

No Brasil, de acordo com o Decreto no 98.816/90, os agrotóxicos podem ser classificados conforme sua classe toxicológica.

Para Almeida (2002) a classificação toxicológica dos venenos agrícolas dispõe da classificação classe toxicológica I produtos extremamente tóxico; DL $50 \mathrm{de} 5 \mathrm{mg} / \mathrm{kg}$ de peso ou menos, faixa vermelha do rótulo, cuja dose de apenas uma pitada ou algumas gotas é capaz de matar uma pessoa adulta. Classe toxicológica II produto altamente tóxico, DL50 de 5-50 mg/kg de peso, faixa amarela no rótulo, cujas doses de algumas gotas a uma colher das de chá é capaz de matar uma pessoa adulta. Classe toxicológica III produto mediamente tóxico, DL 50 de $50-500 \mathrm{mg} / \mathrm{kg}$ de peso, faixa azul no rótulo, cuja dose de uma colher das de chá a duas colheres das de sopa, é capaz de matar uma pessoa adulta. Classe toxicológica IV produto pouco tóxico DL 50 de 500 $500 \mathrm{mg} / \mathrm{kg}$ de peso, faixa verde no rótulo, cuja dose de uma colher das de sopa a um copo, é capaz de matar uma pessoa adulta.

Os parâmetros indicam com mais ou relativa precisão o perigo desses pesticidas. Um deles é a dose letal. O parâmetro toxicológico e DL (Dose Letal) 50. Trata-se da quantidade em miligramas de um princípio ativo capaz de matar $50 \%$ dos animais submetidos a testes ou a quantidade experimental que ocasiona a morte de mil gramas de peso vivo. A DL 50 se manifesta diretamente nos sexos geralmente as fêmeas são mais resistentes principalmente em humanos.

Os agrotóxicos em geral contêm metais pesados, substâncias químicas como cádmio,
chumbo e mercúrio, que não são eliminados pelo organismo e que vão se acumulando
nos tecidos do corpo. Os metais pesados estão associados ao aparecimento de câncer,
deficiência no sistema nervoso central e imunológico, distúrbios genéticos, etc. É difícil,
no entanto, ter certeza sobre os efeitos do emprego de agrotóxicos sobre a saúde,
devido à biodiversidade de alimentos que comemos e ao fato de que as pessoas são
vulneráveis em graus variados. Os limites máximos para resíduos tóxicos e o nível
aceitável de ingestão diária só indicam o que se estima como limite para a saúde das
pessoas. (Consumo sustentável. Manual de Educação, 2002, p.35).

Os agrotóxicos são usados em inúmeras culturas comerciais, seja no controle de pragas, doenças ou inços. Na região do Médio Alto Uruguai é basicamente nas culturas de soja, feijão, milho, trigo, fumo, frutíferas, hortaliças e em dessecação total de áreas para plantio direto. (INFORMATIVO, 1995).

Segundo a OMS, há 20.000 óbitos/ ano em conseqüência da manipulação, inalação e consumo direto de pesticidas, nos países em desenvolvimento, como o Brasil. Os agrotóxicos organofosforados entre os quais inclui o Tamoron causam basicamente três tipos de seqüelas neurológicas após intoxicação aguda devido à exposição crônica: polineuropatia retardada (fraqueza progressiva e ataxia das pernas, podendo evoluir para uma paralisia flácida), síndrome intermediária (paralisia que afeta principalmente os músculos flexores do pescoço, músculos da perna e respiratórios e diarréia intensiva) e efeitos comportamentais (insônia ou sono perturbado, ansiedade, retardo de reações, dificuldade de concentração e uma variedade de seqüelas psiquiátricas: apatia, irritabilidade, esquizofrenia, dificuldade de raciocínio, falhas da memória e depressão). (PINHEIRO, 2004)

O Sistema Nacional de Informações Tóxico-Farmacológicas (Sinitox) da Fundação Osvaldo Cruz 


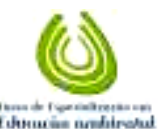

REMOA

FRANZ \& LINK, vol.(4), n4, p. 672-695, 2011.

\section{Monografias Ambientais (e-ISNN: 2236-1308)}

registra em média 7000 intoxicações humanas de veneno por ano. Porém a Organização Mundial da Saúde e o Ministério da Saúde estimam que mais de 300 mil pessoas se intoxiquem anualmente no Brasil e em torno de 50.000 pessoas morram.

A situação de exposição aos agrotóxicos se agrava quando se trata de crianças e mulheres, pois são mais suscetíveis a esses produtos. As mulheres, por exemplo, já nascem com os óvulos todos e quando estes são lesados não há volta. Os homens ao menos no período ativo têm condições de produzir espermatozóides. Estudos feitos sobre os eleitos hormonais dos organoclorados, dioxinas e outras moléculas de agrotóxicos mostram que elas imitam hormônios presentes no homem e na mulher. Os hormônios participam na determinação do sexo nas mulheres grávidas. Com isso, o filho de uma mãe contaminada poderá nascer com deformações nos órgãos reprodutivos, podendo inclusive ser hermafrodita. $O$ impacto dos agrotóxicos nos hormônios humanos e animais é preocupante, pois a produção de espermatozóides nos homens brasileiros caiu pela metade, ou seja, em 50\% de 1963 a 1993. (PRESTES, 2005).

As intoxicações agudas causadas por agrotóxicos estão se intensificando. Os trabalhadores rurais recebem pouca ou nenhuma orientação sobre o modo correto de aplicar agrotóxicos. Portanto o uso abusivo de agrotóxicos e a falta de informações afetam a saúde e o meio ambiente. Resíduos nos alimentos ultrapassam os limites toleráveis. Pois o homem, consumidor final na cadeia alimentar, vai acumulando os agrotóxicos, ou as lesões bioquímicas com conseqüências graves para saúde sob o ponto de vista crônico. (PRESTES, 2005.p.19).

A lei dos agrotóxicos №. 7802, aprovada em 1989, proíbe o registro de produtos que possam provocar câncer, defeitos na criança em gestação (teratogênese) e nas células (metagênese).

Ensinaram ao agricultor que agrotóxico era "defensivo agrícola", ou "remédio", capaz de acabar com todas as pragas da lavoura. Não foi dito que o incremento de pesticidas na atividade resultaria no aparecimento de novas pragas, ou pragas mais resistentes, que causaria danos à saúde e ao meio ambiente.

A produção agrícola se serve de capital intensivo e há pouco aproveitamento da mão- de-obra, onde uma das conseqüências é o emprego de insumos, cujas fórmulas e princípios ativos são importados. As maiores vítimas deste modelo agrícola são o povo através das intoxicações gradativas ou fulminantes e do consumo de alimentos com resíduos tóxicos. (RENNER, 1985).

O uso indiscriminado dos agrotóxicos na lavoura vem causando grandes prejuízos econômicos à saúde humana e ao meio ambiente. Isso demonstra a necessidade de levar aos agricultores o conhecimento, quanto à maneira correta de aplicação dos agrotóxicos (ANVISA, 2006). Somente assim, ir-se-á diminuir os danos à saúde, à preservação do meio ambiente e o aumento da qualidade dos produtos.

É importante dizer que os agricultores que usam agrotóxicos não são vilões, não o fazem por mal, mas foram vítimas de uma campanha que as multinacionais, juntamente com os governos, orquestraram para criar uma dependência dos agricultores em relação à indústria. Assim, tragicamente, a tecnologia do controle de pragas é dominada por um pequeno número de grandes indústrias químicas. Estas só conseguem lucros se os agricultores e a população no mundo inteiro acreditarem que a sobrevivência da humanidade depende da aplicação cada vez maior de agrotóxicos. O crescimento rápido da população exige uma maior produção de alimentos, o que faz do agrotóxico artigo de necessidade primária para se obter maior rendimento nas 


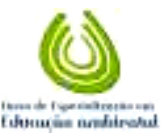

FRANZ \& LINK, vol.(4), n4, p. 672-695, 2011.

REMOA

\section{Monografias Ambientais (e-ISSN: 2236-1308)}

plantações. Por outro lado, o uso desses produtos causa uma série de problemas na natureza e na saúde humana. Nestes aspectos comprometendo as condições de vida das pessoas, pois causam várias doenças e a perda de recursos naturais devido à contaminação dos mesmos por estes produtos. (AENDA, 2005).

De acordo com Campos (2008, p. 180) uma das atividades potencialmente poluidora é a agricultura, que se tornou uma das maiores ameaças para o ambiente, mesmo reconhecendo que não é possível a humanidade sobreviver sem ela, no entanto ela começa a demonstrar seu esgotamento, como ocorre com a possibilidade de faltar alimentos. Entre os principais problemas está a artificialização da agricultura, com a utilização de produtos químicos em larga escala, com máquinas agrícolas e outros aparatos tecnológicos de alto potencial poluidor e gerador de aquecimento do Planeta.

Segundo, (Ruegg et al 1986, p54) os agrotóxicos podem causar diferentes efeitos nos ambientes: presença de resíduos no solo, água e ar; lesões fitotoxicidade; modificação na vegetação (por ação de herbicidas); presença de resíduos em animais domésticos e silvestres; efeitos fisiológicos como inviabilidade de ovos de aves; mortalidade de algumas espécies; eliminação de insetos benéficos; alteração das populações de insetos; desenvolvimento de resistência; resíduos acima dos toleráveis; ingestão de alimentos com resíduos; exposição ocupacional (operários nas indústrias e trabalhadores agrícolas: intoxicações agudas, subagudas e crônicas); acidentes: envenenamento agudo; mutações de insetos e fungos (RUEGG et al., 1986, p.54). O uso de agrotóxicos contribui para alterar a flora microbiana, responsável, em grande parte, pela fertilidade de um solo. Alguns tipos de venenos comumente usados também são capazes de bloquear sinais químicos que permitem funcionamento de bactérias fixadoras de nitrogênio, fazendo com que o solo na área tratada fique mais pobre deste nutriente, demandando aplicação maior de fertilizantes. (GUAZZELLI, 2009).

Os resíduos dos agrotóxicos que permanecem nos legumes, verduras e frutas podem causar sérios danos à saúde, sem falar dos riscos de intoxicação que o produtor corre no momento da aplicação se não forem tomados os devidos cuidados. Além disso, quando aplicado, parte do produto se espalha pelo ar e outra parte penetra no solo. No solo, parte do veneno é levada pela água das chuvas para os rios que vai contaminar a água e toda a vida aquática. Como na cadeia alimentar um organismo serve de alimento para o outro, acontece um acúmulo de agrotóxicos nos indivíduos.

A mortalidade de peixes, em muitos casos, é devida a poluição causada pelo lançamento nas água de restos de formulações, lavagens de equipamentos de pulverização em riachos rios e lagoas, culturas feitas à margem de águas, lavagem e carregamento de agrotóxicos pelas chuvas, respingos acidentais de formulações de pesticidas em poços, tanques, caixas de água, fontes, riachos, rios, lagoas, aplicação direta de pesticidas nas águas para controlar larvas, mosquitos e vegetação aquática excessiva. Assim as melhores condições da poluição das águas por agrotóxicos são dadas pelas análises dos resíduos em peixes.

Freitas (2001, p.35) analisou os escritos de Carlos Minc atual Ministro do Meio Ambiente no livro ecologia e cidadania, colocando assim seu o posicionamento em relação à ação do homem nas cadeias alimentares o que leva a eliminação dos predadores naturais, devido à utilização dos agrotóxicos: 


\begin{abstract}
A ação do homem nas cadeias alimentares, como é o fato de os agrotóxicos, usados para combater as pragas das lavouras (lagartas, pulgões, formigas, gafanhotos) acaba eliminando também os predadores naturais (sapos, pássaros, etc) na ausência desses predadores naturais, surgem novas pragas e isso leva ao uso de mais veneno para combatê-las. (1998)
\end{abstract}

Dessa forma, instala-se um ciclo contínuo, que leva ao esgotamento do solo, à poluição dos rios, ao endividamento dos pequenos agricultores, pois são forçados a comprar cada vez mais agrotóxicos e fertilizantes para manter o nível de produção. Tudo isso tem ocasionando, também, a introdução de um novo ingrediente na cesta básica do consumidor: o veneno presente nas frutas, legumes, na carne, nos cereais, no leite, em quantidade cada vez mais alarmante. Quem ganha e quem perde? Perdem a natureza, os agricultores endividados e contaminados e consumidores de alimentos mais caros e com maior dose de veneno. Ganham os fabricantes e os vendedores de agrotóxicos. (FREITAS, 2001).

De acordo com a entrevista realizada com Gerlach (2009) responsável do Setor de Meio Ambiente o município de Novo Barreiro convive com a problemática dos agrotóxicos que tem trazido conseqüências negativas ao meio ambiente local:

No ano de 2007, verificou-se que houve várias mortes de aves de pequeno porte no interior do município, concluiu-se que era devido ao uso de Furasin usado no tratamento da semente de milho. Essas sementes eram consumidas pelas aves, pois na hora do plantio do milho, os agricultores não enterravam suficientemente para "esconder" a semente tratada. Na ocasião, fomos para a Rádio Comunitária esclarecer o que estava acontecendo e orientar os agricultores para tomarem os cuidados necessários na hora do plantio para evitar essas mortes. Também acontecem reclamações do uso de herbicidas de uso agrícola no perímetro urbano, procurou-se conversar com as pessoas que o estavam utilizando para que evitem cultivares agrícolas como o soja no perímetro urbano.

A contaminação ambiental no município de Novo Barreiro tem sido um problema público de difícil solução em curto prazo. A utilização de agrotóxicos no município é preocupante, principalmente no que se refere à proteção de mananciais pela falta de postos de abastecimento de pulverizadores e sem critérios para destino das embalagens de agrotóxicos. O uso inadequado e indiscriminado de produtos tóxicos, o mau armazenamento das embalagens tem sido causa de contaminação ambiental. (PREFEITURA MUNICIPAL DE NOVO BARREIRO, 2006).

O uso seguro de produtos fitossanitários exige o uso correto de Equipamento de Proteção Individual. EPI são ferramentas de trabalho que visam proteger a saúde do trabalhador rural, que utiliza os Produtos Fitossanitários, reduzindo o risco de intoxicação decorrentes da exposição. As vias de absorção são: inalatória (nariz), oral (boca), ocular (olhos) e dérmica (pele).

A utilização dos agrotóxicos originou uma nova categoria de resíduos, as de embalagens vazias, resultando num sério problema ambiental. Até pouco tempo, por determinação de Lei Federal, estas embalagens deveriam ser enterradas em covas profundas no solo, feitas especialmente para esta finalidade. Porém grande parte das embalagens eram descartadas em rios, queimadas a céu aberto, abandonadas nas lavouras, enterradas sem critério algum, inutilizando áreas agricultáveis e possibilitando a contaminação de lençóis freáticos, do solo e 


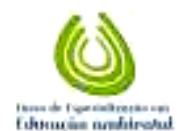

REMOA

FRANZ \& LINK, vol.(4), n4, p. 672-695, 2011.

Monografias Ambientais (e-ISSN: 2236-1308)

do ar. (REVISTA AMIGOS DA NATUREZA, 2006).

Atendendo as exigências da nova lei dos agrotóxicos 9.974/00, todos os envolvidos na cadeia produtiva agrícola passaram a ter responsabilidades sobre o destino final das embalagens vazias de agrotóxicos. Ou seja, o agricultor, o fabricante, o sistema de comercialização e ainda, o poder público.

Segundo o manual de destino final de embalagens vazias de agrotóxicos o principal motivo para darmos a destinação final correta para as embalagens de agrotóxicos é diminuir o risco para a saúde das pessoas e de contaminação do meio ambiente.

A nova legislação federal disciplina a destinação final de embalagens vazias de agrotóxicos e determina as responsabilidades para o agricultor, o revendedor, o fabricante e para o governo na questão de educação e comunicação. $O$ não cumprimento destas responsabilidades poderá implicar em penalidades previstas na legislação específica e na lei de crimes ambientais (Lei 9.605 de 13/02/98), com multas e até penas de reclusão.

Segundo a revista Amigos da Natureza (2006, p.10) a indústria tem a responsabilidade de recolher as embalagens vazias devolvidas as unidades de recebimento e dar a correta destinação final (reciclagem ou incineração). Também deve implementar, em colaboração com o poder público, programas educativos de orientação e conscientização do agricultor.

Segundo dados extraídos do site Agência Brasil (2009) o Brasil é exemplo para países desenvolvidos no que se refere ao recolhimento de embalagens vazias de agrotóxicos:

\footnotetext{
O Brasil já recolheu mais de 100 mil toneladas de embalagens de agrotóxicos usados pelos agricultores desde que entrou em operação o Instituto Nacional de Processamento de Embalagens Vazias (Inpev), em março de 2002, que é uma entidade sem fins lucrativos criada para gerir a destinação final de embalagens de agrotóxicos. A taxa de retorno chegou, em 2008, a 95\%, bem superior a de outros países que tem programas semelhantes. Segundo o coordenador de agrotóxicos do Ministério da Agricultura, Luís Carlos Rangel, o Canadá, o Japão e os Estados Unidos têm taxa de retorno entre $20 \%$ e $30 \%$ das embalagens. O diferencial brasileiro, segundo ele, é o sistema de fiscalização aplicado aqui, no qual o revendedor e o comprador são identificados e a devolução das embalagens monitorada, inclusive com punições previstas. Cerca de $95 \%$ das embalagens recolhidas sai recicladas e as restantes incineradas. O ganho ambiental gerado pelo volume reciclado em seus anos do programa equivale, segundo o instituto, ao plantio de 491 mil árvores, ou 98 toneladas de gás carbônico. O sistema gera mais de 2,5 mil empregos diretos e indiretos. É considerado um exemplo mundial de um trabalho onde participam: agricultor, a revenda e, principalmente, a indústria, subsidiando esse trabalho. Faz o que era um lixo rural, que contaminava o meio ambiente, numa mercadoria útil, através da produção de tubos para fibra ótica, de recipientes plásticos para lubrificantes, até embalagens para defensivos agrícolas, sendo uma cadeia de cooperação exemplar e que poderia servir para outros setores que estão preocupados com o meio ambiente e com a sustentabilidade.
}

Segundo dados extraídos do site diário popular (2009) o Brasil encaminhou 11.164 toneladas de embalagens vazias de agrotóxicos ao destino final ambientalmente correto (reciclagem ou incineração) de janeiro a maio deste ano, conforme dados da INPEV. Esse volume representa um crescimento de $16,2 \%$ em relação ao mesmo período do ano passado, quando foram destinados 9.609 toneladas. Com esse índice, o país ultrapassou a marca das 10 mil toneladas, sendo que somente em maio seguiram para o destino 3,04 mil toneladas de embalagens vazias. 


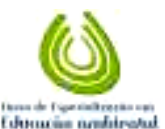

\section{FRANZ \& LINK, vol.(4), n4, p. 672-695, 2011. Monografias Ambientais (e-ISSN: 2236-1308)}

REMOA

Percebe-se claramente a importância não só da criação das leis, mas de sua aplicação e fiscalização, gerando a preocupação de muitos agricultores no valor da multa caso descumpram a legislação.

A efetividade da lei também é prejudicada pela falta de recursos para fiscalizar e pela ausência de autoridades para aplicar as penalidades, fruto também da permissividade do Estado por não ter investido em tecnologias menos agressivas. Entre as grandes propriedades agrícolas, a ingerência política, decorrente do poder econômico, debilita a fiscalização. Entre as pequenas e médias propriedades não capacitadas e sem assistência técnica, a fiscalização costuma ser sensível à precariedade social e econômica apresentada e não aplicando a lei em vigor.

A preocupação com a preservação ambiental apareceu com mais força nas últimas décadas em conseqüência da conduta irresponsável do homem diante da natureza, que busca somente explorar os recursos naturais, esquecendo que esses são finitos e esgotáveis, visão do mundo capitalista, marcado pela preocupação única e absoluta com o lucro, resultando no descaso com as questões ambientais e esquecimento dos valores. A Educação Ambiental tem sido um desafio para especialistas e educadores, pois não é fácil transformar a consciência ingênua e capitalista do homem em uma consciência crítica para que se possa ter ética em nossa conduta frente às questões ambientais.

A Educação Ambiental é definida como um processo no qual incorporamos critérios sócioambientais, ecológicos, éticos e estéticos nos objetivos didáticos da educação, com o objetivo de construir novas formas de pensar incluindo a compreensão da complexidade e das emergências e inter-relações entre os diversos subsistemas que compõe a realidade. $O$ ponto central é a preservação/recuperação do ambiente é algo que atinge a todos. (KUHNE, 2008).

Assim, temas como a aplicação de agrotóxicos e suas conseqüências negativas ao meio ambiente e a saúde humana, causam ampla preocupação.

Conforme a Constituição Federal de 1988, em seu art. 225, capítulos VI do Meio Ambiente:

Todos têm o direito ao Meio Ambiente ecologicamente equilibrado, bem de uso comum do povo e essencial à sadia qualidade de vida, impondo-se ao poder público e a coletividade o dever de defendê-lo e preservá-la para as presentes e futuras gerações.

A Educação Ambiental apresenta uma nova dimensão a ser incorporada ao processo educacional, trazendo toda uma recente discussão sobre as questões ambientais e as conseqüentes transformações de conhecimentos, valores e atitudes diante de uma nova realidade a ser construída.

Guimarães (1995, p.8) coloca que o mundo que se quer mais equilibrado e justo, requer engajamento pessoal e coletivo de educadores e educandos no processo de transformações sociais. Com o passar do tempo à humanidade vai afirmando uma consciência individual. Paralelamente, cada vez mais vai deixando de se sentir integrada com o todo e assumindo a noção de parte da natureza. Nas sociedades atuais o ser humano afasta-se da natureza. A individualização chegou ao extremo do individualismo. O ser humano, totalmente desintegrado do todo, não percebe mais as relações de equilíbrio da natureza. Age de forma desarmônica sobre o ambiente causando grandes desequilíbrios ambientais. 


\begin{abstract}
O mundo é super povoado e as cidades substituem com seus atrativos artificiais a beleza natural, e o homem corre risco de sufocar-se em seu próprio eixo. Os lagos e mar, inevitavelmente poluídos. O ar está irrespirável em muitas cidades e o lixo urbano e industrial acumula-se por toda a parte. As pragas ceifam os campos agrícolas e os agrotóxicos utilizados para impedir sua proliferação concorrem para o aumento da poluição das águas e o envenenamento da população. (GUIMARÃES, 1995, p 10).
\end{abstract}

Precisa-se de uma nova maneira de pensar a Educação Ambiental, sabe-se que o caminho é cheio de desafios, mas deve-se buscar uma nova maneira de agir e pensar sobre os recursos naturais.

O homem, como ser pensante, precisa encontrar caminhos pelos quais seja possível trilhar o desenvolvimento com a preservação ambiental, a preocupação não deve ser apenas local ou individual, mas deve ter abrangência planetária, ser uma preocupação somente econômica através do desejo de lucratividade e ameaça ao financeiro, mas uma preocupação que se concentre no desenvolvimento sustentável, na relação harmônica entre homem e natureza, sobrevivendo dela sem comprometê-la, este é o principal responsável por um direito/e dever em relação com meio ambiente. (CAMPOS, 2008).

Nessa perspectiva de promoção da mudança ambiental, deve a educação assumir uma posição de destaque na tentava de construir fundamentos da sociedade sustentável, com mudanças culturais visando à instauração de uma ética ecológica, que deve desencadear as mudanças sociais na direção preservacionista comprometida com a inclusão humana, com o desenvolvimento sustentável.

Para Capra (2006, p. 23) há soluções para os principais problemas de nosso tempo, algumas delas até mesmo simples. Mas requerem uma mudança radical em nossas percepções, no nosso pensamento e nos nossos valores. E, de fato, estamos agora no princípio dessa mudança fundamental de visão do mundo na ciência e na sociedade. Porém, essa compreensão ainda não despontou entre a maioria de nossos líderes políticos. O reconhecimento de que é necessário uma profunda mudança de percepção e de pensamento para garantir a nossa sobrevivência ainda não atingiu a maioria dos líderes das nossas corporações, nem os administradores e os professores das nossas grandes universidades. Nossos líderes não só deixam de reconhecer como diferentes problemas estão inter- relacionados; eles também se recusam a reconhecer como as suas assim chamadas soluções afetam as gerações futuras. A partir do ponto de vista sistêmico, as únicas soluções viáveis são as soluções "sustentáveis".

É de grande necessidade a construção de alternativas rápidas e eficientes em relação à aplicação dos agrotóxicos que ofereçam subsídios para organizar ações, levando as pessoas a tomarem consciência da gravidade dessa situação, mas também identificar possibilidades de superação.

Deve haver uma relação harmoniosa entre o homem e natureza, não esquecendo que este necessita da natureza para sobrevivência, por isso, não se pode "afastar" da natureza, mas agir de forma sustentável sem agredi-la, sabendo que os recursos naturais são finitos e esgotáveis. O processo educativo pode fazer a diferença, tentar mudar a mentalidade das pessoas e em harmonia com a natureza garantir a sustentabilidade para as presentes e futuras gerações, pois é da natureza que sobreviverão as futuras gerações. 
REMOA

\section{Monografias Ambientais (e-ISSN: 2236-1308)}

\section{MATERIAIS E MÉTODOS}

O projeto: Agrotóxicos e a Educação Ambiental destina-se a comunidade escolar da Escola Municipal de Ensino Fundamental Zeferino Brasil da localidade de Três Passinhos município de Novo Barreiro.

O município de Novo Barreiro/RS localiza-se na região Noroeste do Estado do Rio Grande do Sul, distante $360 \mathrm{~km}$ da capital do Estado Porto Alegre. Com uma área de 12.350 hectares, conta atualmente com uma população de 3.858 habitantes sendo na área rural 2.838 e 1.020 na área urbana. Segundo dados do IBGE (2007) 92\% da população sobrevive da atividade primária que desenvolve também o comércio local, geração de impostos, enfim a geração de renda, $7 \%$ da população ocupa o setor secundário e $1 \%$ o setor terciário. As principais atividades econômicas desenvolvidas no município são: a produção de soja, milho, trigo, leite, bovinos e erva-mate.

O município divide-se nas seguintes localidades: Três Passinhos, Bela Vista, Poço Preto, Linha Biriva, Linha Progresso, Vista Alegre, Coxilha Rural, Olaria, Jogareta, Posse dos Camargos, Prestes, Fagundes e Volta Braba.

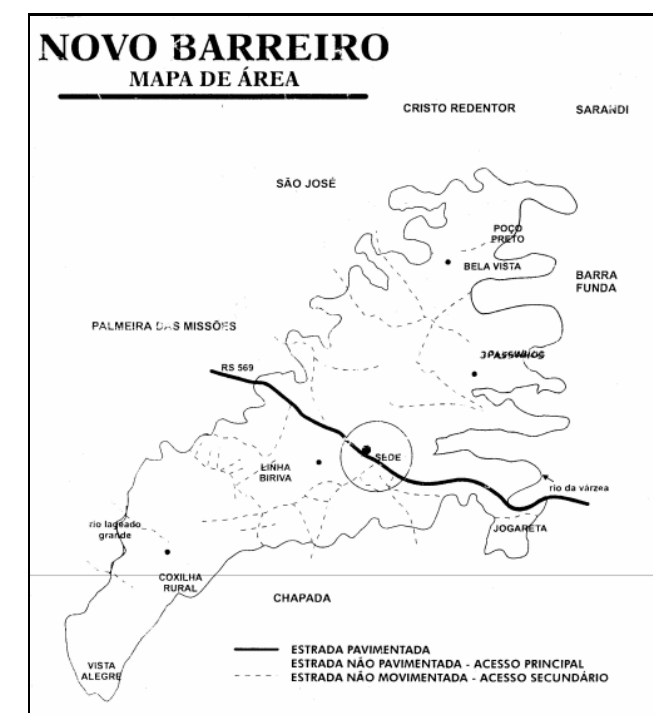

Figura 2 - Mapa do município de Novo Barreiro (Prefeitura Municipal de Novo Barreiro, 2009).

É de essencial importância o cuidado com a utilização de agrotóxicos, uma vez que este é utilizado em grande escala pelos agricultores, entrando também o papel da Educação Ambiental que deve desenvolver nos indivíduos, as potencialidades necessárias a fim de formar cidadãos com visão crítica, atuantes com iniciativa, responsabilidade e consciência, por isso, precisa-se de reflexões sobre a problemática da contaminação ambiental por 
agrotóxicos que vem se agravando pela falta de esclarecimento e consciência do agricultor, pois estes na grande maioria, não usam medidas preventivas, equipamentos de segurança, aplicando veneno sem proteção e sem ter a noção exata do perigo que representa para sua saúde e de seus familiares, para o meio ambiente e o consumidor.

Sendo Novo Barreiro um município essencialmente agrícola observa-se a necessidade de esclarecer a importância de certos cuidados referentes ao uso de agrotóxicos como os efeitos nocivos aos seres vivos e ao meio ambiente, pois os mesmos podem ficar acumulados no organismo meses e até dezenas de anos, favorecendo a intoxicação e suas graves conseqüências causam lesões diversas no organismo entre alterações genéticas passando de geração para geração. Precisa-se partir da realidade para construir uma verdadeira Educação Ambiental. A agricultura familiar se evidencia, ocorrem maiores riscos ao produtor, sendo este setor o mais prejudicado devido ao baixo potencial de investimentos.

\begin{abstract}
A Contag Confederação que representa os trabalhadores rurais garante que quem se contamina primeiro é o agricultor. O relatório da Anvisa alerta que o maior problema está na pequena propriedade, onde o agricultor tem menos instrução e recursos para investir no plantio. Os agrotóxicos são produtos químicos necessários à produção agrícola para controlar pragas na lavoura e, portanto, fundamentais para o agricultor, desde que alguns cuidados sejam tomados, para ter o mínimo de risco, é preciso usar produtos registrados, que são profundamente analisados pelos governos, e não aplicá-los sem Equipamentos de proteção Individual (EPI), recomendado na bula dos químicos e aprovados pelos órgãos de saúde. O engenheiro agrônomo deve ser consultado para indicar o tipo e a quantidade de agrotóxicos para cada cultura, além dos cuidados necessários no momento da aplicação. (RANGEL, 2008. p.12).
\end{abstract}

Segundo dados do Jornal Correio do Povo (2008, p.12) a maior parte dos alimentos contaminados também provém da agricultura familiar, pois estes não tem recursos para consultar um profissional, nestas situações os agricultores, devem ao menos respeitar as orientações da bula dos agrotóxicos, inclusive o cumprimento da determinação em termos de equipamentos de proteção.

Em sua entrevista Gerlach (2009) quando questionada sobre alternativas para tentar diminuir a aplicação de agrotóxicos no município Novo Barreiro, coloca:

É inevitável o uso de agrotóxicos nos moldes econômicos atuais, isso é fato. O uso desses mecanismos de controle são usados sempre em matrizes produtivas que são voltadas para a monocultura, porém os pequenos e micros produtores plantam soja, milho e trigo, em nosso município, tanto que essas 3 culturas estão no topo da produção primária no município. A única forma para diminuir o uso seria implantar alternativas lucrativas para o produtor com culturas que não exijam tanto defensivo agrícola, como é o caso da suinocultura e produção leiteira que hoje correspondem respectivamente por $15 \%$ e $5 \%$ da produção primária, segundo dados do Sistema Sitrago. Um exemplo disso, é que em 2001 vários produtores plantavam fumo, que exige uma carga muito grande de agrotóxicos, essa realidade já mudou e atualmente apenas 2 produtores mantém essa atividade, segundo a Secretária Municipal de Agricultura. Precisa-se de medidas a longo prazo, mas para isso, necessita-se de mudanças na matriz produtiva do município. 
REMOA

\section{Monografias Ambientais (e-ISSN: 2236-1308)}

\section{METODOLOGIA}

O Projeto Agrotóxico e a Educação Ambiental foi desenvolvido na Escola Municipal de Ensino Fundamental Zeferino Brasil da localidade de Três Passinhos, município de Novo Barreiro, instituição de ensino que conta com 105 alunos, sendo 64 alunos no turno da manhã de $5 \underline{a}$ a $8^{a}$ séries. A pesquisa fundamentou-se na abordagem qualitativa, que sugere a investigação dos problemas sociais que utiliza uma concepção metodológica à hermenêutica, que leva em conta a interpretação dos significados contidos no texto.

A característica desse trabalho é a pesquisa ação, pois envolve um plano de ação baseado em objetivos, acompanhamento, observação, investigação, reflexão e desejo de mudança por parte dos educandos.

De acordo com Dias (2000, p.225) a Educação Ambiental, por ser interdisciplinar, por lidar com a realidade, por adotar abordagem que abrange todos os aspectos que compõe a questão ambiental - sócio/cultural, políticas, científico-tecnológico, éticos, ecológicos, etc., pode e deve oportunizar novos processos educativos que levem as pessoas a uma possibilidade de mudança e melhoria do ambiente em que vive.

O projeto se realizou de forma interdisciplinar onde todas as atividades foram planejadas em conjunto com professores e educandos através do diálogo, visando à troca de informações, realizando a prática da pesquisa em grupo com metodologia mais indicada para a possibilidade de cooperação qualitativa.

A Escola Municipal de Ensino Fundamental Zeferino Brasil vem desenvolvendo desde o início do ano letivo o projeto Meio Ambiente: Uma Questão de Conscientização, durante o desenvolvimento das atividades que se realizaram coletivamente, percebeu-se o interesse dos educandos de 5a a 8a séries em debater o tema agrotóxicos onde os mesmos questionaram o destino das embalagens de agrotóxicos na localidade e a aplicação sem equipamentos de proteção individual, uma vez que todos os alunos são filhos de pequenos agricultores agregados e empregados rurais de médio e baixo nível socioeconômico que desenvolvem em suas propriedades a agricultura familiar.

Após averiguou-se o interesse dos professores em participar da referida pesquisa, dando andamento ao projeto ambiental através do tema agrotóxico. Foi decidido coletivamente que o projeto se realizaria com alunos de $5 \underline{a}$ a $8^{\underline{a}}$ séries totalizando 64 alunos, pois os mesmos já fazem parte do projeto sobre meio ambiente da escola.

Foram coletadas sugestões dos alunos sobre atividades que gostariam que se realizasse dentro do tema, posteriormente foram analisadas as possibilidades de realização, ocorrendo à sugestão das seguintes atividades por parte dos educandos: confecção de um folder sobre os agrotóxicos visando à conscientização o qual seria entregue nas residências dos alunos; teatro; pesquisa e apresentação de trabalhos em forma de seminário nas salas de aula, seguido pela socialização entre todas as turmas; palestra sobre os malefícios dos agrotóxicos a saúde humana e o concurso da melhor redação.

Para uma maior compreensão dos educandos sobre a importância da utilização do equipamento de proteção individual e destino correto das embalagens de agrotóxicos se realizaria uma palestra proferida pelo professor Doutor da Universidade Federal de Santa Maria Dionísio Link. Anteriormente a palestra foi planejado a aplicação de um questionário aos educandos participantes do projeto para que se análise a visão que os mesmos tinham a respeito do tema e a maneira como é utilizado os agrotóxicos em sua propriedade. 
Com o objetivo de planejar de forma interdisciplinar as atividades a serem realizadas ocorreu uma nova reunião entre os professores, onde foi decido que a 8 $^{a}$ série através da disciplina de Educação Artística faria a leitura da obra Seu João das Alfaces - Uma introdução à agricultura orgânica, seguindo de análise, debate e dramatização. Um trio composto de alunos cantaria a música Natureza, Espelho de Deus de Chitãozinho e Xororó. Nas aulas de História e Geografia a 8 $^{a}$ série se realizaria uma pesquisa e debate sobre Revolução Verde (surgimento dos agrotóxicos). Nas aulas de Português os alunos de 5 a série realizariam pesquisa em grupos com análise e debate sobre a legislação vigente e o destino das embalagens de agrotóxicos e a criação de desenhos que serão expostos em forma de varal. Nas aulas de Ciências dos alunos de 6a série fariam uma pesquisa sobre os equipamentos de proteção individual e sua importância. A 7ạ série nas aulas de Técnicas Agrícolas realizaria uma pesquisa sobre as conseqüências dos agrotóxicos a saúde do agricultor que os aplica sem equipamento de proteção. Nas aulas de matemática ocorreria a análise das respostas dos educandos ao questionário aplicado onde as respostas seriam transformadas em gráficos pelos educandos e futuramente socializadas as demais turmas.

Planejou-se que após os temas serem pesquisados pelas turmas haveria uma socialização no grande grupo, objetivando estabelecer o diálogo, criatividade, criticidade, troca de conhecimentos e opiniões entre professores e educandos.

Segundo Silva $(2005$, p. 20) a interdisciplinaridade é um espaço privilegiado para interrelações, a troca de conhecimentos e a convivência humana, onde $o$ saber constantemente trafega no movimento frenético das intervenções da realidade de onde todos são condutores desse conhecimento inclusive para além do espaço escolar.

\section{RESULTADOS E DISCUSSÕES}

Refletindo sobre o trabalho desenvolvido na Escola Municipal de Ensino Fundamental Zeferino Brasil com alunos de $5^{\underline{a}}$ série a $8^{\underline{a}}$ séries e quadro docente, percebeu-se que os educandos têm consciência sobre os problemas ambientais e em específico sobre a utilização dos agrotóxicos, mas que em suas famílias percebem a possível falta de conhecimento e esclarecimento, pois muitas vezes o agricultor não é informado e assim não tem conhecimento sobre as conseqüências negativas que está trazendo a sua própria saúde e ao meio ambiente, ou simplesmente se nega a dar o destino correto as embalagens e a se proteger, faltando à tomada de consciência sobre a problemática. Isso foi visível na medida em que a metodologia se desenvolvia e os resultados eram analisador e discutidos entre os professores.

Durante a realização da metodologia 58 alunos de 5a a $8^{a}$ séries responderam a um questionário anterior a realização das palestras, sobre 0 destino das embalagens, conhecimento dos riscos que a utilização de agrotóxicos sem equipamentos de proteção individual pode trazer a saúde humana, utilização de equipamentos de proteção individual, casos de intoxicação, entre outros. O que reverteu nos seguintes resultados: 
FRANZ \& LINK, vol.(4), n4, p. 672-695, 2011.

Monografias Ambientais (e-ISSN: 2236-1308)

REMOA

\section{Quem aplica agrotóxico em sua propriedade?}

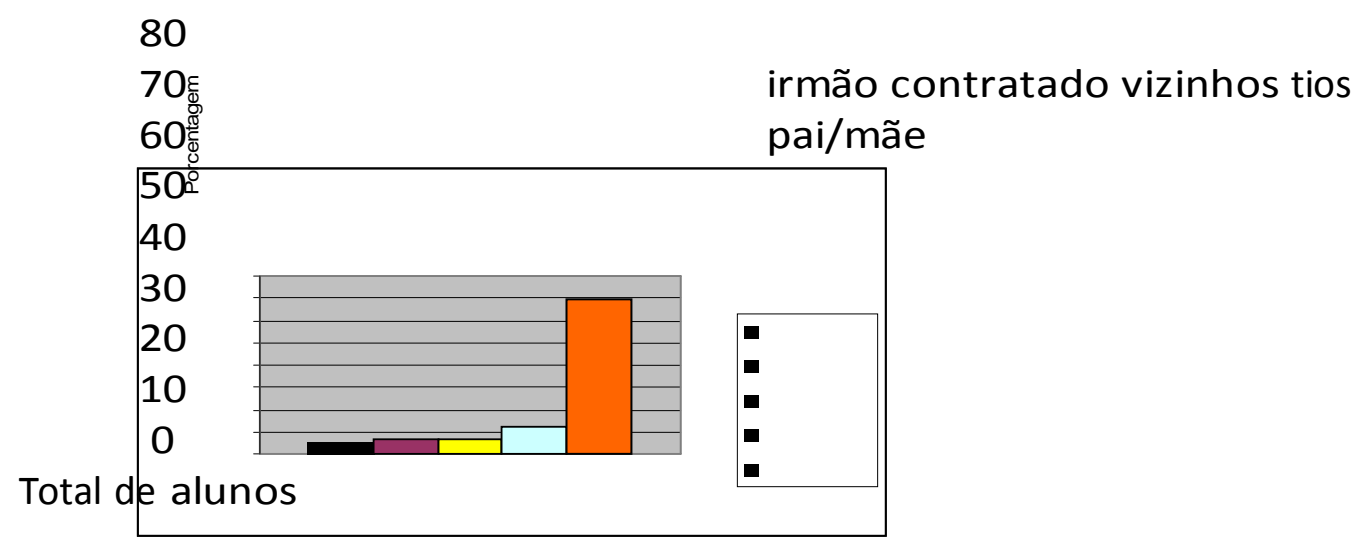

Figura 4 - Gráfico das respostas da questão 2.

Dos alunos entrevistados 69,03\% coloca que a aplicação dos agrotóxicos acontece em sua propriedade pelo pai/mãe, $12 \%$ pelos tios, 6,9\% pelos vizinhos, 6,9\% por pessoas contratadas pela família e pelo irmão 5,17\%. Percebe-se que os agricultores têm consciência que os agrotóxicos devem ser aplicados por pessoas maiores de idade. $\mathrm{O}$ dado que ressalta que 6,9\% dos agrotóxicos é aplicado por pessoas contratadas são segundo os educandos pela impossibilidade dos pais em aplicá-los, pois acabam se sentindo mal após aplicar ou porque não possui maquinários para realizar a aplicação. 
FRANZ \& LINK, vol.(4), n4, p. 672-695, 2011.

Monografias Ambientais (e-ISSN: 2236-1308)

REMOA

Em sua propriedade o que é feito com as embalagens após a utiliz ação do produto?

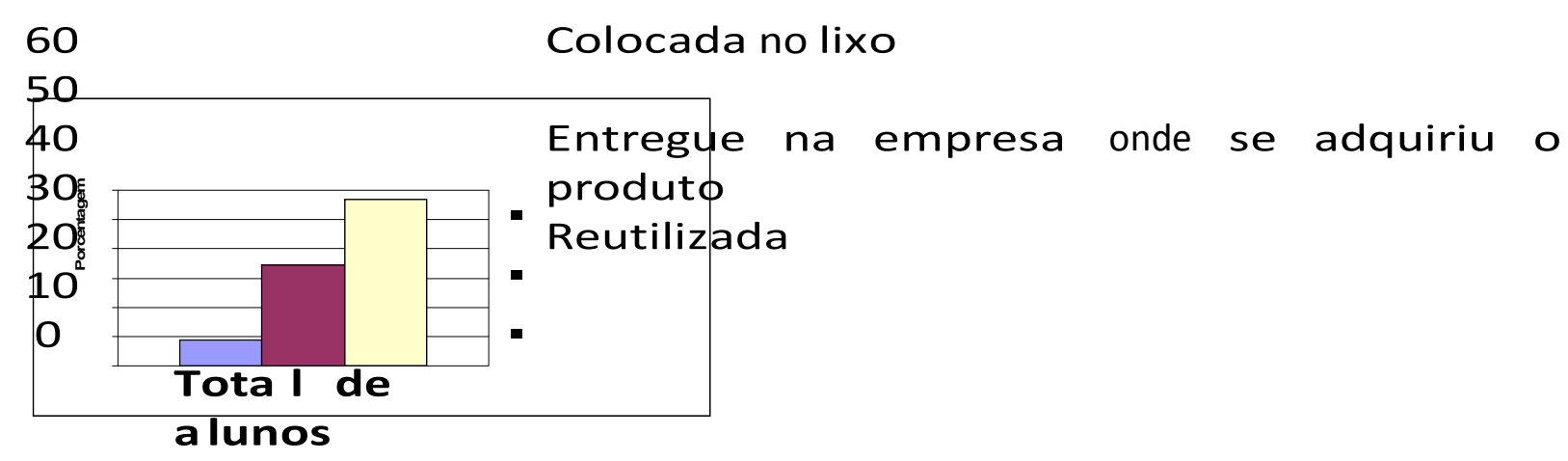

Figura 5 - Gráfico das respostas da questão 4.

Quanto ao destino das embalagens de agrotóxicos 56,90\% reutiliza, 34,48\% entrega na empresa onde adquiriu o produto e $8,62 \%$ é colocada no lixo. Segundo ANDEF (2005), o principal motivo para dar destinação final correta às embalagens de agrotóxicos é diminuir o risco à saúde das pessoas que aplicam e prevenir contaminação do meio ambiente. Percebe-se que muitos agricultores na localidade onde se desenvolveu o projeto reutilizam as embalagens inclusive para alimentar os animais que existem na propriedade ou para proteger os palanques de cercas contra a ação da chuva, mostrando que possuem pouca consciência ambiental. O destino final das embalagens vazias de agrotóxicos requer a participação de todos os agentes envolvidos na fabricação, comercialização, utilização, licenciamento, fiscalização e monitoramento das atividades relacionadas com o manuseio, transporte, armazenamento e processamento dessas embalagens. 
FRANZ \& LINK, vol.(4), n4, p. 672-695, 2011.

Monografias Ambientais (e-ISSN: 2236-1308)

REMOA

Em sua propriedade quando se aplica os agrotóxicos é utilizado EPI?

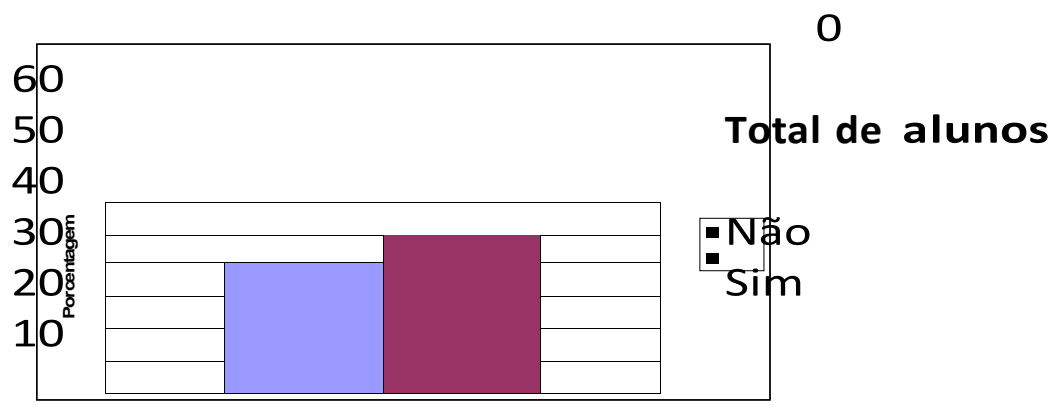

Figura 6 - Gráfico das respostas da questão 5 
FRANZ \& LINK, vol.(4), n4, p. 672-695, 2011.

REMOA

$56,90 \%$ dos alunos entrevistados afirmam que em sua propriedade quem aplica os agrotóxicos utiliza equipamentos de proteção individual e 43,10\% não utiliza. Sabe-se que os agricultores são as maiores vítimas de contaminação e exposição dos agrotóxicos, para evitar isso, os agricultores devem fazer uso do equipamento de proteção individual, pois o descuido pode ser fatal e causar graves conseqüências à saúde do agricultor. $O$ uso do Equipamento de Proteção Individual é fundamental para proteger as vias de absorção do produto tóxico pelo organismo, protegendo a saúde do agricultor e evitando as várias conseqüências que o uso incorreto dos agrotóxicos pode trazer a saúde.

Você conhece alguém que esteve contaminado por agrotóxicos?

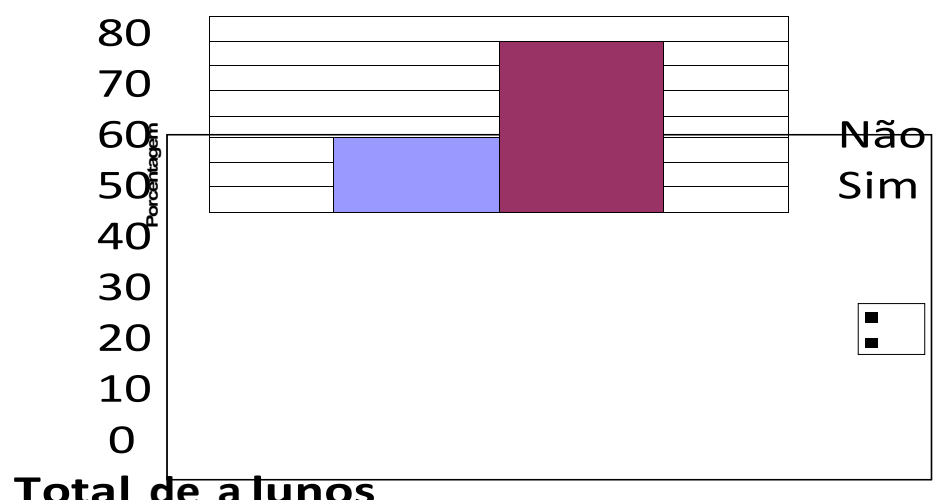

Total de alunos 
Figura 8 - Gráfico das respostas da questão 8.

67,24\% dizem conhecer alguém que esteve contaminado por agrotóxicos e 32,76\% não conhecem ninguém contaminado. O número impressiona principalmente quando se considera a forte pressão exercida pela indústria internacional responsável pela produção e distribuição dos agrotóxicos sobre o mercado consumidor brasileiro. Tal fato aliado às dificuldades na assistência fornecida as empresas que comercializam os agrotóxicos e por parte do poder público ajuda a estabelecer uma situação de risco extremo a saúde do agricultor que necessita ser informado sobre o perigo que está correndo ao aplicar os agrotóxicos sem equipamento de proteção.

Após a realização da palestra proferida pelo Engenheiro Agrônomo professor Doutor da UFSM Dionísio Link sobre o uso correto de Equipamento de Proteção Individual e destino final de embalagens vazias de agrotóxicos aconteceram mudanças na maneira de pensar dos participantes, onde anteriormente a palestra achavam correto reutilizar as embalagens de agrotóxicos, desconheciam as exigências da legislação e as conseqüências do descumprimento da mesma.

De grande debate e análise durante o decorrer do projeto foi à forma de utilização dos agrotóxicos em suas propriedades onde estes passaram a compreender a importância da proteção, bem como, do destino correto das embalagens de agrotóxicos, e o que é de grande importância levaram os questionamentos e conhecimento adquirido na escola a família, cobrando mudanças de atitudes por parte dos pais.

Com o objetivo de verificar se ocorreu a mudanças de opinião e até mesmo de atitudes após o término da palestra foi entregue o mesmo questionário aos mesmos alunos. Em sala de aula aconteceu uma análise sobre a nova visão adquirida pelos alunos onde os mesmos puderam expressar sua realidade e vivencias sobre a utilização de agrotóxicos.

Nas aulas de matemática aconteceram à análise das primeiras respostas dos alunos, o que foi transformado em gráficos, socializado para os demais alunos e exposto no mural da escola.

Com uma metodologia interdisciplinar aconteceram pesquisas com os seguintes temas: as conseqüências dos agrotóxicos a saúde humana e a composição química de alguns agrotóxicos utilizados na agricultura; revolução Verde (surgimento dos agrotóxicos); legislação vigente e o destino das embalagens de agrotóxicos; utilização correta de Equipamento de Proteção Individual. Após a referida pesquisa ocorreu à socialização de todos os assuntos onde cada turma apresentou para as demais suas pesquisas. Assim professores e alunos puderam expor sua opinião e analisar criticamente a problemática dos agrotóxicos.

Para complementar o tema sobre os agrotóxicos e suas conseqüências a saúde humana foi convidado o Doutor Ivan Vargas Júnior médico do Programa da Saúde Familiar do município que proferiu uma palestra para os alunos participantes do projeto.

A partir dos conhecimentos adquiridos aconteceu a confecção de um folder que alertasse a população barreirense sobre o perigo que os agrotóxicos causam quando aplicados sem equipamento de proteçãoindividual, destino incorreto das embalagens e as determinações da legislação. O folder foi distribuído na comunidade de Três Passinhos e localidades onde os educandos residem pelos alunos e diretora Aline Franz.

Conclui-se que o trabalho interdisciplinar levou os educandos a questionar, criticar, opinar, conhecer, participar, formar opinião e a defender está opinião, isso foi essencial para a mudança 


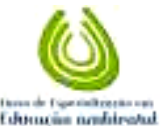

\title{
FRANZ \& LINK, vol.(4), n4, p. 672-695, 2011. Monografias Ambientais (e-ISSN: 2236-1308)
}

REMOA

de atitude, resultados que puderam ser observados durante as palestras, pesquisas, produções textuais, criação de desenhos, socializações e entrega de folder. Durante a entrega do folder foi visível por parte dos alunos o desejo de mudança, colocando aos agricultores o conteúdo do folder e explicando criticamente as conseqüências que se pode trazer a saúde e ao meio ambiente caso o agricultor não tomar as devidas precauções, além da grande preocupação que possuem com a saúde dos pais que utilizam os agrotóxicos.

\section{CONSIDERAÇÕES FINAIS}

O uso de agrotóxicos é uma problemática na atualidade, pela forma como é utilizado pelo agricultor que ao dispor do produto não faz uso de equipamento de proteção individual e descarta as embalagens em locais inadequados, por isso, deve-se implantar medidas para evitar o uso inadequado dos agrotóxicos, através da atualização da legislação em vigor, visando à proteção eficiente dos trabalhadores expostos aos produtos tóxicos, promovendo uma fiscalização adequada sobre a implantação do receituário agrônomo. Conscientizar a população sobre a mortalidade e a morbidade relacionada com envenenamentos, estimulando a população a atuar na fiscalização do uso adequado e seguro de agrotóxicos. Existe cada vez mais a necessidade de se buscar um novo modelo de produção que seja ecologicamente sustentável e socialmente justo.

\begin{abstract}
Assim, como fica nossa saúde? E a qualidade de vida? Precisamos iniciar uma rápida caminhada ao encontro do problema numa tentativa de amenizar, instruindo os nossos produtores rurais, usuários de produtos químicos, já que as informações não vêm dos fabricantes destes produtos. É necessário encontrar uma solução urgente, por um ambiente saudável. (FREITAS, 2001 p.02).
\end{abstract}

Precisa-se desenvolver ações educativas buscando promover mudanças no meio rural e nos demais, levando o homem a analisar, criticar, denunciar e sugerir mudanças visando melhoria na qualidade de vida no Planeta.

Percebe-se a grande importância deste projeto participativo sobre agrotóxicos, onde os alunos se sentiram parte integrante, podendo opinar e participar da elaboração da metodologia, enfim tomando decisões. É visível a mudança de mentalidade dos educandos, comparando a visão muitas vezes ultrapassada que traziam de casa, onde achavam correto reutilizar as embalagens de agrotóxicos desconhecendo os malefícios que os agrotóxicos podem trazer ao meio ambiente e a saúde humana. Para o resultado positivo deste projeto foi de fundamental importância o engajamento e participação de toda a escola, professores, funcionários, educandos, coordenação pedagógica a até mesmo o apoio da Secretaria de Saúde, onde realizando atividades interdisciplinares, refletindo e analisando criticamente a situação dos agrotóxicos nas propriedades e município de maneira coletiva, buscando ações de mudanças frente à problemática dos agrotóxicos e acima de tudo levando para as famílias aquilo que aprenderam na escola, tentando mudar a mentalidade dos pais ou simplesmente levando o conhecimento.

A escola desempenha uma importante oportunidade de construir com alunos e a comunidade, novos conceitos, mudanças de atitudes e valores, proporcionando aos mesmos, a 
tomada de posição consciente e participativa a respeito das questões ambientais, bem como, a busca de ações diárias que contribuam para a melhoria da questão ambiental, fazendo com que se comprometam com uma série de valores, se sentido como parte integrante do meio, para participarem de sua construção e melhoria.

Cada um deve fazer a sua parte, cada ser humano deve se transformar em ator e agente de divulgação dos princípios que norteiam as normas da ecologia, do civismo e da cidadania.

Conviver em harmonia com o meio ambiente e natureza, eis o segredo de pessoas inteligentes e conscientes, que possuem sensibilidade ambiental e que sabem fazer de suas vidas, de seu trabalho, de suas ações uma verdadeira dádiva do céu.

Ao criar o homem, Deus confiou-lhe a guarda pacífica da natureza, exortando-o à convivência responsável e resguardando o meio ambiente de qualquer violência ou agressão. Não criou os seres para subjugar o homem. Mas para ser-lhes útil... "Que vos sirvam..." (Casalli, 2009 p. 20).

\section{REFERÊNCIAS}

AENDA (2005) - Fins das embalagens no campo-lixo tem destino e prazo inteligentes. Disponível em < www.aenda.com.br> Acesso em 25/07/2009.

AgênciaBrasil. Disponível em: http://www.agenciabrasil.gov.br/noticias/2009/02/20/materia.2009-0220.0943529208/view. Acesso em: 22 de maio. 2009.

ALMEIDA, P. J. Intoxicação por agrotóxicos: Informações selecionadas para abordagem clínica e tratamento. 1 a ed. São Paulo: Andrei, 2002.

BRASIL. Lei Federal no. 9.974 de 06/06/2000. Altera a lei federal no. 7.802 de 11 de julho de 1989 que dispõe sobre agrotóxicos.

BRASIL. Lei Federal no 7.802 de 11/07/1989. Dispõe sobre os agrotóxicos.

BRUM, A. J. Modernização da agricultura no planalto gaúcho. ljuí: Fidene, 1983.

CAMPOS, A.V. Os desafios da ecologia social frente ao aquecimento global. Complexidade e conhecimento: tempos e espaços de educação. Frederico Westphalen: URI, 2008.

CAPRA, F. A Teia da vida: uma nova compreensão cientifica dos sistemas vivo; tradução Newton Roberval Eichemberg. São Paulo: Cultrix, 2006.

CONSTITUIÇÃO FEDERAL DE 1988. Art. 225, Cap. VI - Meio Ambiente.

CONSUMO sustentável: manual de educação. Brasília: Consumers Internacional/ MMA/IDEC, 2002.

Diário Popular: Disponível em: http://www.diariopopularpr.com.br/joomla/index.php?option=com. Acesso em: 03 de agosto. 2009.

DIAS, G.F. Educação Ambiental: princípios e práticas. 6ạed. São Paulo: Gaia, 1992. FREITAS, M.M.L. A ação dos agrotóxicos na natureza. Santa Maria: UFSM, 2001. GLOBO RURAL. Produtos \& mercados insumos. Ed, no $287,2009$.

GUIMARÃES, M. A dimensão ambiental na educação. 8a ed.: 1995. Disponível em: 


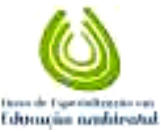

FRANZ \& LINK, vol.(4), n4, p. 672-695, 2011.

REMOA

\section{Monografias Ambientais (e-ISSN: 2236-1308)}

http://books.google.com.br/books?hl=pt-. Acesso em 10 de agosto de 2009.

Informativo. Ano I no. 02. Frederico Westphalen: URI, 1995;

KUHNE, C.F.C. O processo de Educação Ambiental e sua aplicação no Ensino Fundamental. Complexidade e conhecimento: tempos e espaços de educação. Editora da URI, Frederico Westphalen: URI, 2008.

MED/MMA/UNESCO. Vamos cuidar do Brasil: conceitos e práticas em Educação Ambiental na escola. Brasília: Ministério da Educação, Coordenação Geral de Educação Ambiental: Ministério do Meio Ambiente, Departamento de Educação Ambiental: UNESCO,

2007.

Psolsp. Disponível em: http://psolsp.org.br/?p=2292. Acesso em 15 de outubro, 2009.

PINHEIRO, S. Agrotóxicos e o produtor rural. Disponível em: www. preservacaolimeira.com.br. Acesso em: 20/02/2004.

Prefeitura Municipal de Novo Barreiro. CD Perfil do município de Novo Barreiro, 2006. PRESTES, R. M. Avaliação do entendimento dos agricultores do Médio Alto Uruguai

sobre agrotóxicos. Frederico Westphalen: URI, 2005.

RANGEL, L. Agrotóxicos: risco maior ao produtor. Correio do Povo. Porto Alegre, 2008.

RENNER, M. Ecologia: evitar o perigo. Antes que seja tarde. Porto Alegre: Mundo Jovem, 1985.

Revista Amigos da Natureza. Agrotóxicos eles podem estar no seu prato. Dezembro, 2006.

RUEGG, E. F. et al. O Impacto dos Agrotóxicos. O ambiente, a saúde e a sociedade. São

Paulo: Ícone Ltda, 1986.

SILVA, J. E. Interdisciplinaridade na área das ciências da natureza, matemática e suas tecnologias. 2005.

SIQUEIRA, S.L. E KRUSE, L.H.M. Agrotóxicos e saúde humana: contribuição dos profissionais do campo da saúde. Ver. Esc. Enferm. USP v 42 n. 3. São Paulo, 2008. 